06.5;08

\title{
Селективный рост методом молекулярно-пучковой эпитаксии массивов нитевидных нанокристаллов GaN на процессированных $\mathrm{SiO}_{x} / \mathrm{Si-подложках}$
}

\author{
(C) В.О. Гридчин ${ }^{1}$, К.П. Котляр ${ }^{1}$, Р.Р. Резник ${ }^{2}$, Л.Н. Дворецкая ${ }^{1}$, А.В. Парфеньева ${ }^{3}$, \\ И.С. Мухин ${ }^{1,2}$, Г.Э Цырлин ${ }^{1-5}$ \\ ${ }^{1}$ Санкт-Петербургский национальный исследовательский Академический университет им. Ж.И. Алфёрова РАН, \\ Санкт-Петербург, Россия \\ ${ }^{2}$ Университет ИТМО, Санкт-Петербург, Россия \\ ${ }^{3}$ Физико-технический институт им. А.Ф. Иофффе РАН, Санкт-Петербург, Россия \\ ${ }^{4}$ Институт аналитического приборостроения РАН, Санкт-Петербург, Россия \\ ${ }^{5}$ Санкт-Петербургский государственный электротехнический университет „ЛЭтИ“, Санкт-Петербург, Россия \\ E-mail: gridchinvo@yandex.ru
}

Поступило в Редакцию 13 июля 2020 г.

В окончательной редакции 27 июля 2020 г.

Принято к публикации 27 июля 2020 г.

\begin{abstract}
Продемонстрирована возможность селективного роста упорядоченных массивов нитевидных нанокристаллов $\mathrm{GaN}$ с помощью молекулярно-пучковой эпитаксии на процессированных методом фотолитографии по микросферическим линзам подложках $\mathrm{SiO}_{x} / \mathrm{Si}$ без предварительного формирования затравочных слоев. Исследовано влияние температуры подложки на морфологические свойства полученных массивов нитевидных нанокристаллов. Экспериментально выявлены оптимальные ростовые параметры, обеспечивающие режим селективного роста нитевидных нанокристаллов $\mathrm{GaN}$.
\end{abstract}

Ключевые слова: $\mathrm{GaN}$, нитевидные нанокристаллы, молекулярно-пучковая эпитаксия, морфологические свойства, селективный рост, микросферная литография.

DOI: 10.21883/PJTF.2020.21.50194.18463

Одним из основных направлений исследований в области современной физики твердого тела является создание низкоразмерных оптоэлектронных структур на основе III-N полупроводниковых материалов, интегрированных с кремниевой технологией. К таким материалам относятся прежде всего GaN, AlN и InN. Это прямозонные полупроводниковые соединения, обладающие при комнатной температуре шириной запрещенной зоны $0.7(\mathrm{InN}), 3.4(\mathrm{GaN})$ и $6.2 \mathrm{eV}(\mathrm{AlN})$, которые формируются преимущественно в кристаллической структуре типа вюрцит [1]. При этом синтез двумерных слоев высокого кристаллического качества на основе таких соединений на поверхности кремниевых подложек затруднен вследствие существенного различия их параметров кристаллических решеток и температурных коэффициентов расширения. Одним из возможных решений данной проблемы является синтез нитевидных нанокристаллов (ННК). ННК - это (квази)одномерные кристаллические наноструктуры, длина которых значительно превышает их диаметр. Благодаря морфологии ННК упругие напряжения, возникающие в синтезируемой структуре, релаксируют на боковых гранях нанокристаллов. Вследствие этого количество дефектов в ННК значительно уменьшается, что приводит к высокому кристаллическому качеству синтезируемого материала [2].

Известно, что синтез III-N ННК на кремнии зачастую сопровождается высокой плотностью нанокристаллов вплоть до их сращивания [3,4]. Как следствие, это накладывает ограничения на создание радиальных гетеропереходов (типа ядро-оболочка) на основе III-N полупроводниковых материалов. В настоящее время таким гетеропереходам уделяется повышенное внимание. В частности, они способствуют снижению негативного влияния пиннинга уровня Ферми и эффекта Штарка на оптоэлектронные свойства синтезируемых структур [5,6]. Таким образом, активное внимание исследователей уделяется развитию технологий селективного роста упорядоченных массивов III-N ННК.

В соответствии с современными технологиями роста упорядоченные массивы III-N ННК синтезируют на подложках с паттернированной поверхностью. Подготовка таких подложек заключается в создании отверстий в ингибиторном слое (например, $\mathrm{SiO}_{x}$ или Тi), сформированном на поверхности подложки, методом электроннолучевой литографии. Также на предварительном этапе селективного роста на подложках с паттернированной поверхностью обычно формируют затравочный слой AlN [7,8]. Однако осаждение затравочного слоя AIN перед ростом НHK GaN может негативно сказываться на транспортных свойствах $\mathrm{GaN} / \mathrm{Si}$-гетероперехода [9]. В свою очередь недостаток классического подхода к подготовке подложек методом электронно-лучевой литографии заключается в получении малой площади резистивных наноструктур, что обусловлено построчным экспонированием. 


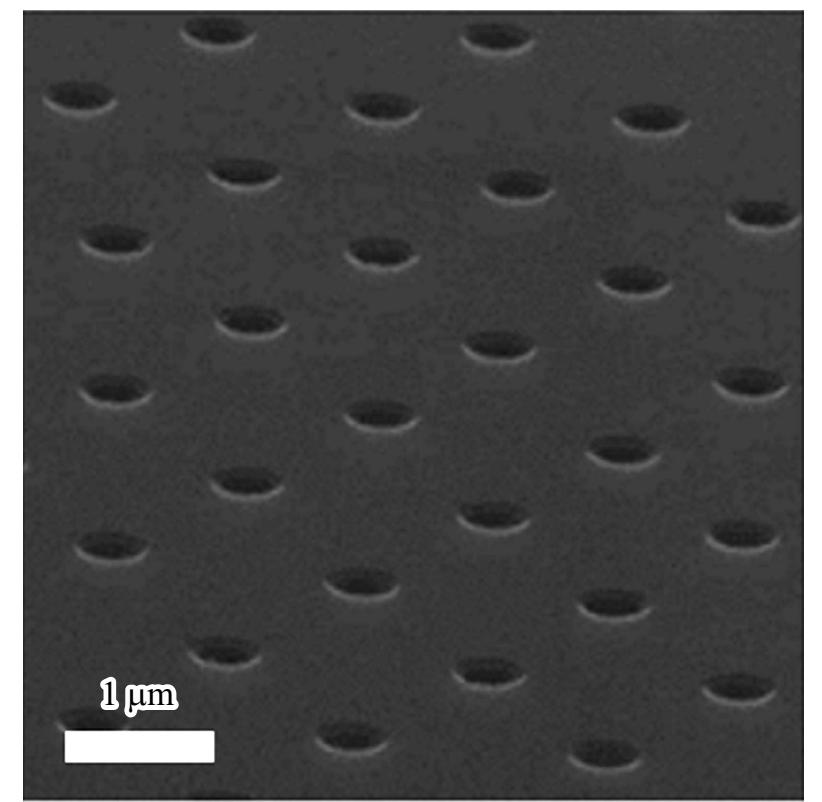

Рис. 1. Типичное РЭМ-изображение поверхности процессированных подложек $\mathrm{SiO}_{x} / \mathrm{Si}$ с отверстиями.

С целью уменьшения времени и стоимости подготовки подложек в настоящей работе использовался метод фотолитографии по микросферическим линзам для формирования отверстий в слое $\mathrm{SiO}_{x}$ на поверхности кремния. Такой метод позволяет относительно недорого и быстро изготавливать упорядоченные массивы отверстий на большей площади и контролируемой плотности в ингибиторном слое для последующего роста ННК [10]. В представленной работе было исследовано влияние температуры подложки $\left(T_{s}\right)$ на морфологические свойства массивов НHК $\mathrm{GaN}$, сформированных методом молекулярно-пучковой эпитаксии (МПЭ) на процессированных подложках $\mathrm{SiO}_{x} / \mathrm{Si}$ без использования затравочных слоев AlN.

Эксперименты по росту массивов НHК GaN проводились при использовании установки МПЭ Riber Compact 12, оснащенной эффузионным источником галлия и плазменным источником азота. Морфологические свойства образцов были исследованы с помощью растрового электронного микроскопа (РЭМ) Supra 25 Zeiss. В качестве подложек использовались пластины кремния ориентации (111), легированные фосфором. На поверхности кремниевых пластин был сформирован оксид $\left(\mathrm{SiO}_{x}\right)$ толщиной $50 \mathrm{~nm}$ методом термического прокисления в атмосфере при температуре $850-950^{\circ} \mathrm{C}$. Затем с помощью метода фотолитографии по микросферическим линзам $\mathrm{SiO}_{2}$ и сухого травления были сформированы отверстия в оксидном слое на $\mathrm{Si}$-подложках $[11,12]$. На рис. 1 представлено типичное РЭМ-изображение поверхности процессированных подложек $\mathrm{SiO}_{x} / \mathrm{Si}$. Хaрактерный диаметр отверстий составил порядка $0.3 \mu \mathrm{m}$, a среднее расстояние между ними - $1 \mu \mathrm{m}$ при поверхностной плотности $10^{8} \mathrm{~cm}^{-2}$, что определялось диа- метром используемых $\mathrm{SiO}_{2}$-микросфер. Далее в рамках данной работы были синтезированы пять образцов с массивами НHK $\mathrm{GaN}$, различающихся между собой только ростовой температурой подложки $\left(T_{s}\right)$. Для этого подготовленные подложки загружались в ростовую камеру и нагревались до $870^{\circ} \mathrm{C}$ для термической очистки поверхности. В этот момент давление в ростовой камере составляло $7 \cdot 10^{-8}$ Torr. После этого $T_{s}$ понижали до ростовой и инициировали источник азотной плазмы. $T_{s}$ образца устанавливалась в диапазоне $810-830^{\circ} \mathrm{C}$ с шагом $5^{\circ} \mathrm{C}$ и была постоянной во время каждого ростового процесса. Поток галлия из источника, измеренный с помощью датчика Байярда-Альперта, составлял $2 \cdot 10^{-7}$ Torr. Источник азотной плазмы работал при мощности $450 \mathrm{~W}$ с потоком газообразного азота $0.4 \mathrm{sccm}$. Мощность источника устанавливалась исходя из наибольшей интенсивности свечения плазмы.

Предварительный контроль состояния поверхности образца и процесса формирования ННК в режиме реального времени in situ осуществлялся методом дифракции быстрых электронов на отражение (ДБЭО). Через час роста GaN на картинах ДБЭО появлялись объемные рефлексы, соответствующие вюрцитной фазе $\mathrm{GaN}$ (рис. 2).

На рис. 3 представлены типичные РЭМ-изображения массивов НHК $\mathrm{GaN}$ на процессированных подложках $\mathrm{SiO}_{x} / \mathrm{Si}$, синтезированных при различных $T_{s}$. Морфологические свойства синтезированных ННК представлены в таблице. Исследования поверхностной морфологии образцов показали, что в диапазоне ростовых температур 810-820 ${ }^{\circ} \mathrm{C}$ HНК $\mathrm{GaN}$ формируются как на $\mathrm{Si}$ в отверстиях слоя $\mathrm{SiO}_{x}$, так и на остаточной поверхности $\mathrm{SiO}_{x}$. При этом ННК в отверстиях в слое $\mathrm{SiO}_{x}$ формируются преимущественно в направлении $\langle 111\rangle$, что свидетельствует об их эпитаксиальной связи с подложкой Si. Средняя поверхностная плотность ННК, сформировавшихся на $\mathrm{SiO}_{x}$ при $T_{s}=810-820^{\circ} \mathrm{C}$, составляет $2.5 \cdot 10^{9} \mathrm{~cm}^{-2}$, a на $\mathrm{Si}$ она равна плотности отверстий $\sim 10^{8} \mathrm{~cm}^{-2}$. Как видно из таблицы и представленных на рис. 3

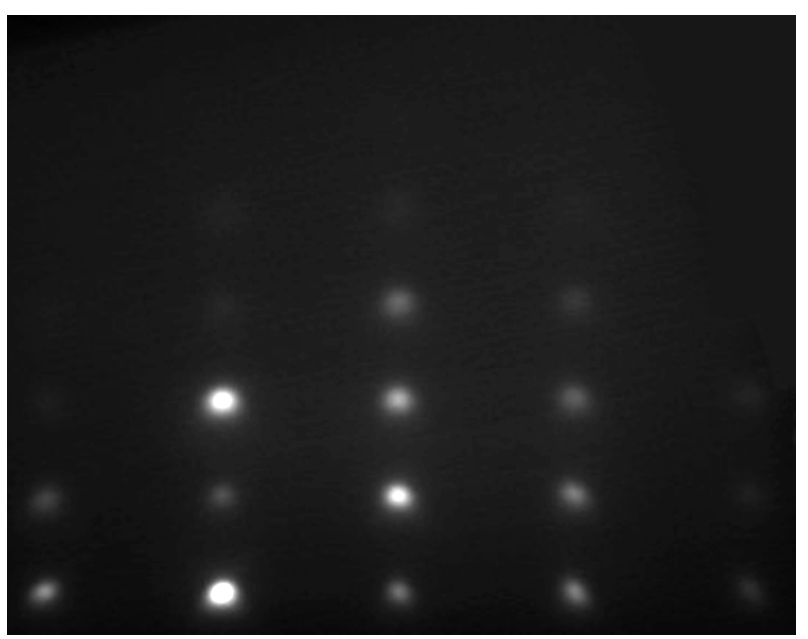

Рис. 2. Типичная картина ДБЭО от ННК $\mathrm{GaN}$ через час роста при $T_{s}=825^{\circ} \mathrm{C}$ на процессированных подложках $\mathrm{SiO}_{x} / \mathrm{Si}$. 


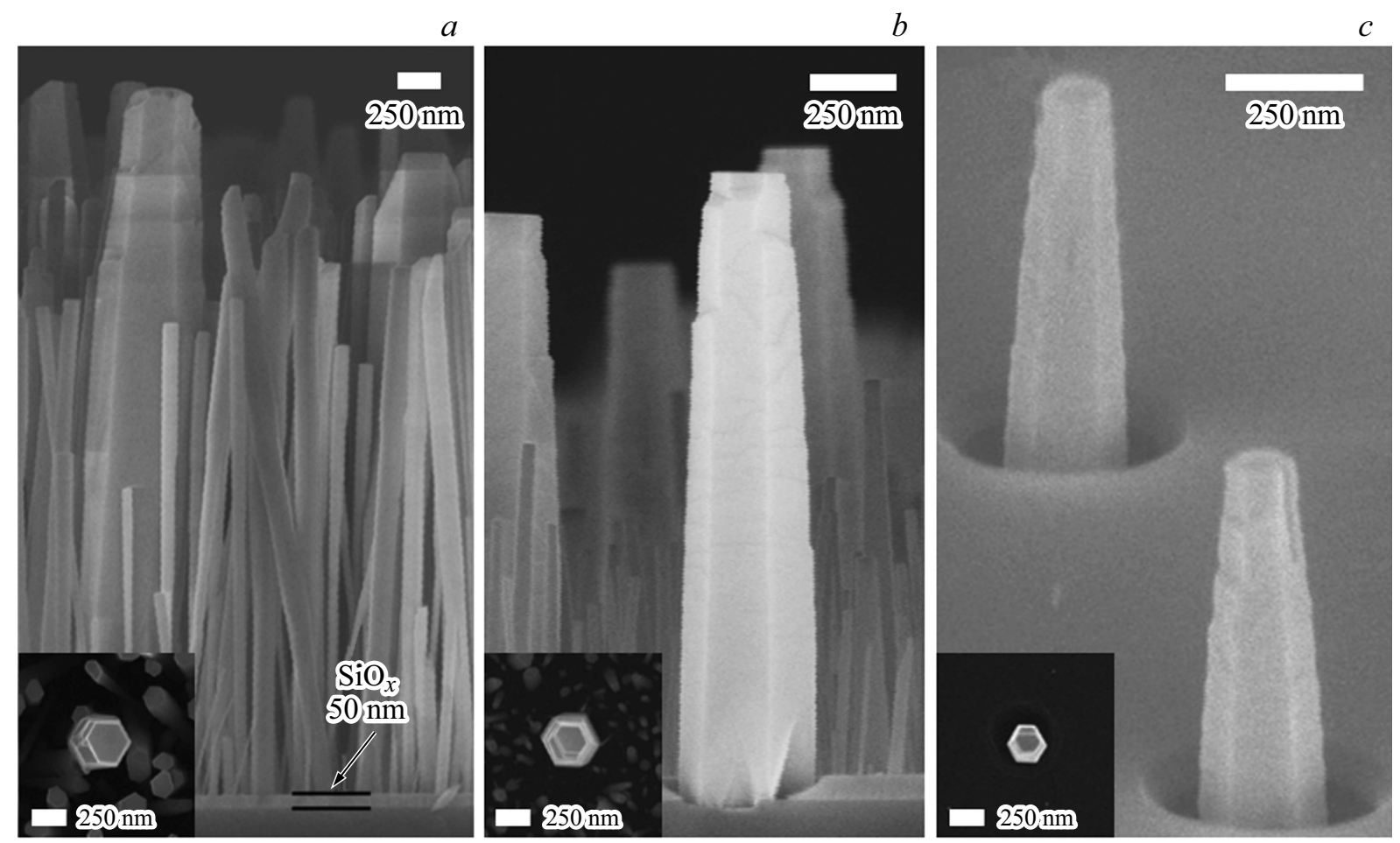

Рис. 3. Типичные РЭМ-изображения НHК $\mathrm{GaN}$, сформированных на процессированных подложках $\mathrm{SiO}_{x} / \mathrm{Si}$ при температуpax $815(a), 820(b)$ и $825^{\circ} \mathrm{C}(c)$. На вставках показаны соответствующие ННК в геометрии „вид сверху“.

РЭМ-изображений, высоты и диаметры НHК на $\mathrm{Si}$, сформировавшихся в отверстиях слоя $\mathrm{SiO}_{x}$, превышают аналогичные параметры ННК, сформировавшихся непосредственно на $\mathrm{SiO}_{x}$, в диапазоне от 1.5 до 10 раз соответственно. Это связано с меньшим коэффициентом прилипания $\mathrm{Ga}$ (sticking coefficient) на поверхности $\mathrm{SiO}_{x}$, чем на $\mathrm{Si}$. С увеличением ростовой температуры от 810 до $825^{\circ} \mathrm{C}$ диаметры и высоты ННК уменьшаются для наноструктур, сформированных как на $\mathrm{Si}$, так и на $\mathrm{SiO}_{x}$. Это связано с уменьшением радиальной и аксиальной скоростей роста ННК по причине увеличения десорбции адатомов $\mathrm{Ga}$ при повышении температуры. В свою очередь при температуре $T_{s}=825^{\circ} \mathrm{C}$ достигается режим селективного роста НHК $\mathrm{GaN}$, и их формирование наблюдается только в отверстиях в слое $\mathrm{SiO}_{x}$. Это объясняется увеличением длины поверхностной диффузии адатомов $\mathrm{Ga}$ с повышением температуры и, следовательно, увеличением вероятности миграции адатомов, находящихся на поверхности $\mathrm{SiO}_{x}$, в отверстия. При дальнейшем увеличении ростовой температуры до $830^{\circ} \mathrm{C}$ процессы десорбции адатомов $\mathrm{Ga}$ начинают преобладать над формированием кристаллитов $\mathrm{GaN}$, и образование ННК не наблюдается. Следует отметить, что полученные результаты качественно совпадают с представленными в работе [7], где селективный рост массивов НHК GaN наблюдался при $T_{s}=830^{\circ} \mathrm{C}$ и использовании Ті-масок для упорядочения.

Таким образом, в работе исследованы температурные зависимости для селективного МПЭ-роста массивов
Морфологические свойства выращенных образцов

\begin{tabular}{|c|c|c|c|c|}
\hline $\begin{array}{c}\text { Температура } \\
\text { подложки } \\
T_{s},{ }^{\circ} \mathrm{C}\end{array}$ & $\begin{array}{c}\text { Высота } \\
\text { ННК } \\
\text { на } \mathrm{Si}, \mu \mathrm{m}\end{array}$ & $\begin{array}{c}\text { Высота } \\
\text { НHК } \\
\text { на } \mathrm{SiO}_{x}, \mu \mathrm{m}\end{array}$ & $\begin{array}{c}\text { Диаметр } \\
\text { HНК } \\
\text { на } \mathrm{Si}, \mathrm{nm}\end{array}$ & $\begin{array}{c}\text { Диаметр } \\
\text { HНК } \\
\text { на } \mathrm{SiO}_{x}, \mathrm{~nm}\end{array}$ \\
\hline 810 & 3. & 2.77 & 390 & 100 \\
\hline 815 & 2. & 1.75 & 370 & 70 \\
\hline 82 & 1.5 & 0.78 & 300 & 30 \\
\hline 825 & 0.7 & - & 230 & - \\
\hline
\end{tabular}

HНК GaN. НHК были синтезированы селективно без предварительного формирования буферных или затравочных слоев непосредственно в отверстиях в слое $\mathrm{SiO}_{x}$ на $\mathrm{Si}$-подложках, подготовленных методом фотолитографии по микросферам и сухого травления. Результаты исследований показали, что при МПЭ-росте оптимальная температура подложки с точки зрения морфологии и селективности массивов НHК $\mathrm{GaN}$ на процессированных подложках $\mathrm{SiO}_{x} / \mathrm{Si}$ составляет $825^{\circ} \mathrm{C}$.

\section{Финансирование работы}

Работа по выращиванию структур выполнена при поддержке Министерства науки и высшего образования в части государственного задания № 0791-2020-0003. Исследования экспериментальных образцов проведены при поддержке Российского фонда фундаментальных исследований (проект № 18-02-40006 мега). Подготов- 
ка кремниевых подложек выполнена при поддержке Министерства науки и высшего образования в части государственного задания№ 0791-2020-0005.

\section{Конфликт интересов}

Авторы заявляют, что у них нет конфликта интересов.

\section{Список литературы}

[1] Bi W.W., Kuо H.H., Ku P., Shen B. Handbook of GaN semiconductor materials and devices. Florida: CRC Press, 2017. 686 p.

[2] Дубровский В.Г., Цырли Г.Э., Устинов В.М. // ФТП. 2009. Т. 43. В. 12. С. 1585-1628. [Пер. версия: 10.1134/s106378260912001x].

[3] Consonni V. // Phys Status Solidi RRL. 2013. V. 7. N 10. P. 699-712. DOI: $10.1002 /$ pssr.201307237

[4] Дубровский В.Г., Тимофеева М.А. // Письма в ЖТФ. 2013. T. 39. B. 2. C. 61-67.

[5] Calarco R., Stoica T., Brandt O., Geelhaar L. // J. Mater. Res. 2011. V. 26. N 17. P. 2157-2168. DOI: $10.1557 / j m r .2011 .211$

[6] Fernández-Garrido S., Auzelle T., Lähnemann J., Wimmer K., Tahraoui A., Brandt O. // Nanoscale Adv. 2019. V. 1. N 5. P. $1893-1900$. DOI: $10.1039 / \mathrm{c} 8 \mathrm{na} 00369 \mathrm{f}$

[7] Schuster F., Hetzi M., Weiszer S., Garrido J.A., Mata M., Magen C., Arbiol J., Stutzmann M. // Nano Lett. 2015. V. 15. N 3. P. $1773-1779$. DOI: $10.1021 / \mathrm{nl} 504446 \mathrm{r}$

[8] Roshko A., Brubaker M., Blanchard P., Harvey T., Bertness K.A. // Crystals. 2018. V. 8. N 9. P. 366.

DOI: $10.3390 /$ cryst 8090366

[9] Bolshakov A.D., Fedorov V.V., Shugurov K.Yu., Mozharov A.M., Sapunov G.A., Shtrom I.V., Mukhin M.S., Uvarov A.V., Cirlin G.E., Mukhin I.S. // Nanotechnology. 2019. V. 30. N 39. P. 395602. DOI: $10.1088 / 1361-6528 / a b 2 c 0 c$

[10] Zhang Z., Geng C., Hao Z., Wei T., Yan Q. // Adv. Colloid Interface Sci. 2016. V. 228. P. 105-122.

DOI: $10.1016 /$ j.cis.2015.11.012

[11] Dvoretckaia L.N., Mozharov A.M., Fedorov V.V., Bolshakov A.D., Mukhin I.S. // J. Phys.: Conf. Ser. 2018. V. 1124. N 2. P. 022042.

DOI: $10.1088 / 1742-6596 / 1124 / 2 / 022042$

[12] Bolshako A.D., Dvoretckaia L.N., Fedorov V.V., Sapunov G.A, Mozharov A.M., Shugurov K.Y., Shkoldin V.A., Mukhin M.S., Cirlin G.E., Mukhin I.S // Semiconductors. 2018. V. 52. N 16. P. 2088-2091. DOI: 10.1134/s1063782618160054 